\title{
A cystic amelanotic melanoma metastasis to the brain: case report
}

\author{
B. Cemil; H. Emmez; N. Oztanır; N. Tokgoz* and F. Dogulu
}

Department of Neurosurgery and Department of Radiology*. Gazi University School of Medicine. Ankara. Turkey.

\section{Summary}

As far as we know, cyst formation in intracranial melanoma is rare, and only 15 cases of intracranial amelanotic melanoma have been reported until now. A yellowish mass was observed in the frontal lobe. The content of the cyst consisted of old hematoma, xanthochromic fluid and necrotic tissue, was evacuated and the cyst wall was totally resected. No abnormal pigmentation was noted in the cyst wall and surrounding brain tissue. The imaging features of metastatic melanomas are distinctive due to the presence of melanin and the propensity for hemorrhage. Both hemorrhage and melanin can produce T1-weighted hyperintensity and T2-weighted signal intensity loss.

KEY WORDS: Melanoma. Brain metastases. Brain abscess.

Metástasis cerebral de un melanoma amelanótico quístico

\section{Resumen}

Que sepamos, la formación quística de un melanoma intracraneal es rara y sólo se han descrito $\mathbf{1 5}$ casos de melanoma intracraneal amilanocítico. Se observó una masa amarillenta en el lóbulo frontal. El contenido del quiste consistía en un hematoma antiguo, con líquido xantocrómico tejido necrótico que se evacuó, con resección total de la pared del quiste. No se encontró ninguna pigmentación anormal en la pared ni en el tejido cerebral adyacente. Las imágenes de los melanomas metastásicos son muy peculiares, debido a la presencia de melanina y a la propensión a la hemorragia. Ambos, hemorragia y melanina pueden producir hiperseñal en T1 e hiposeñal en $T 2$.

PALABRAS CLAVE: Melanoma. Metástasis cerebral. Absceso cerebral

Recibido: 15-01-08. Aceptado: 23-02-08

\section{Introduction}

Cerebral metastases are the most common brain tumours occurring 5-10 times more frequently than primary brain tumours in adults. Cerebral metastases are one of the major causes of morbidity and mortality in cancer patients. The most common sources for cerebral metastases are lung $(50 \%)$, breast $(15-20 \%)$, melanoma $(10 \%)$ and colon $(5 \%)^{1}$. In clinical series, the occurrence of brain metastases in melanoma patients ranges from $6 \%$ to $43 \%$. The incidence of metastases to the brain in patients with advanced melanoma is $36 \%$ to $54 \%$ at autopsy ${ }^{4}$.

In this article, an extremely rare presentation of cerebral metastatic melanoma is reported. Cranial magnetic resonance imaging (MRI) demonstrated a solitary pure cystic lesion in the left frontal lobe. Histopathological examination revealed amelanotic melanoma. The authors aim to discuss the radiographic features of melanomas.

\section{Case Report}

A 29-year-old woman admitted to the hospital with headache and diplopia which were started twenty days ago. Neurological examination revealed left oculomotor nerve and abducens nerve palsy. In the history, two years ago the patient had a flat, irregular shaped nodule $1.5 \times 1.3 \times 0.2 \mathrm{~cm}$ in size, over the right scapula. After an excisional biopsy, melanoma was detected and a wide excision including a 2.5 $\mathrm{cm}$ normal skin margin from the previous incision line and the fascia was performed. Pathological findings indicated a superficial spreading melanoma. The Clark level was III and Breslow's tumor thickness was $2.5 \mathrm{~mm}$. There was no recurrence or metastasis in her follow-ups. The routine laboratory checks were normal. Cranial computed tomography (CT) examination revealed a cystic lesion in the left frontal lobe that showed a ring enhancement on postcontrast images (Fig. 1). On cranial MRI; the cystic lesion had low signal intensity on $\mathrm{T} 1$ weighted images (T1WI) and high signal intensity on $\mathrm{T} 2$ weighted images (T2WI). The cyst wall showed a ring enhancement on postcontrast T1WI (Fig. 2 a, b). 
B. Cemil and col

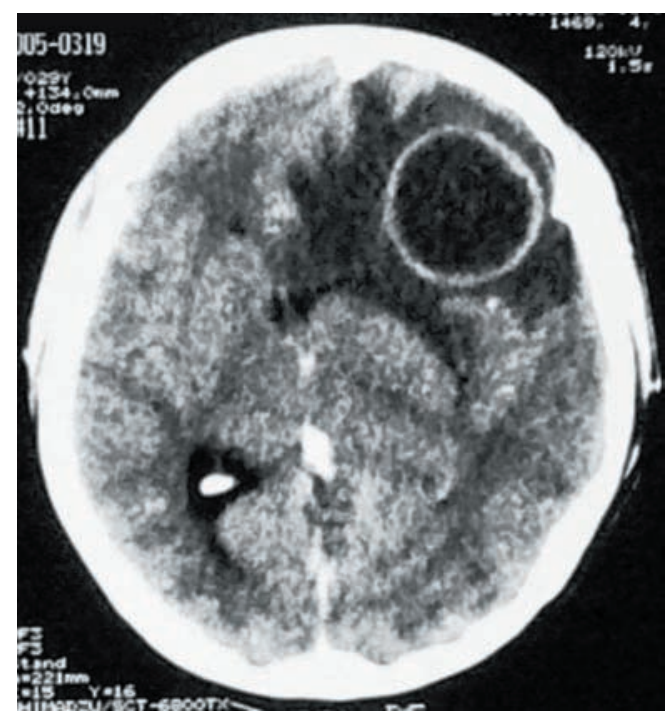

Figure 1. On first admission, postcontrast CT scan demonstrates a cystic lesion in the left frontal lobe that shows ring enhancement. The lesion has marked vasogenic edema.

The patient underwent emergence surgery. Left frontal craniotomy with a total resection of the tumor was performed. Intraoperatively, the mass was intra-axial and consisted of a white yellow colored fluid. Also the tumor was easily dissected from the brain parenchyma. There was no pigmentation on the cyst wall or neighbor parenchyma. Histopathological examination and the melanoma antigen HMB-45, the adjuvant immunohistological marker confirmed the diagnosis of malignant melanoma. The patient was subsequently treated with fractionated whole-brain radiation, followed by chemotherapies. The patient is still recurrence-free at the 12month follow-up evaluation (Fig. $3 \mathrm{a}, \mathrm{b}$ ).

\section{Discussion}

The structures in the head that can be involved by metastases from melanoma include bone, muscle, the nasopharynx and mucosa, the parotid gland, the meninges, the choroid plexus, the internal auditory canal, and the orbit. The brain is the most common site of melanoma metastases in the head.

The clinical course indicated that this tumour was a metastatic melanoma, but the images did not conform to those in normal malignant melanoma, which usually show high signal intensity on T1WI and low signal intensity on T2WI. Differential diagnosis included metastatic melanoma, cystic glial tumour, and brain abscess. The CT and MRI findings of intracranial melanoma have been well documented in the literature. Cranial metastatic melanomas have a high propensity to hemorrhage. Therefore, these lesions show intrinsically increased density on unenhanced CT examinations ${ }^{7}$. Melanoma metastases exhibit a variable
Neurocirugía 2008; 19:365-367

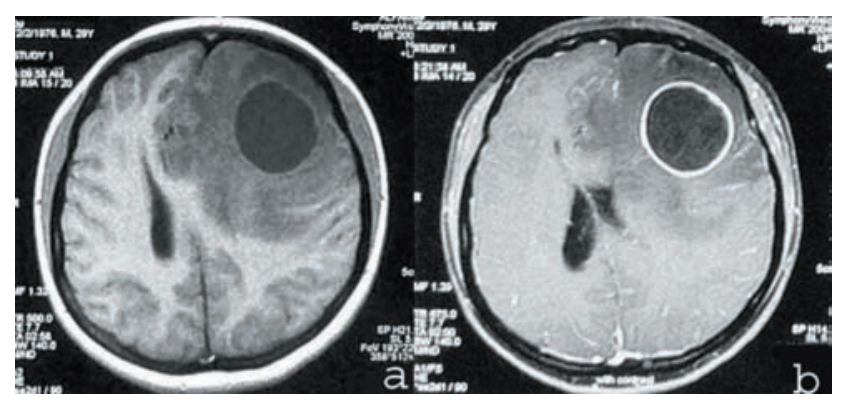

Figure 2. a) Axial precontrast T1WI reveals the left frontal cystic lesion with prominent vasogenic edema; b) Axial postcontrast TIWI demonstrates the cyst with prominent ring enhancement.

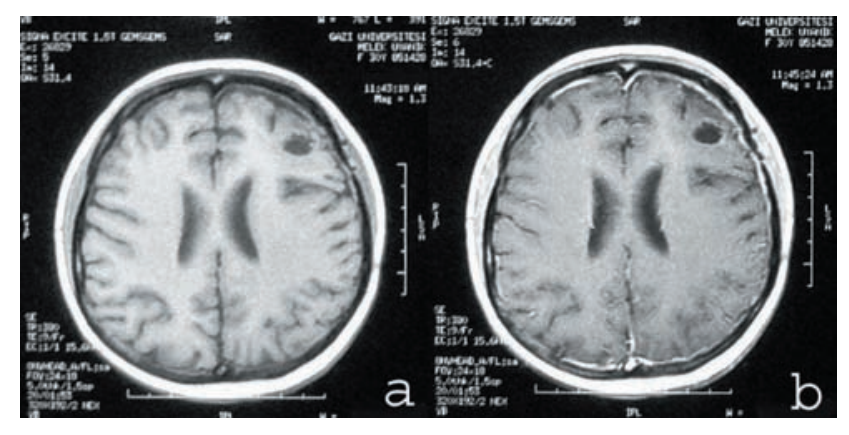

Figure 3. On one-year control MRI; precontrast a) and postcontrast; b) axial T1WI demonstrate the decrease in the size and associated vasogenic edema of the lesion.

MRI pattern that is dependent on several factors. Stable free radicals (indobe semiquinones and semiquinones) within the melanin pigment are paramagnetic and affect a shortening of $\mathrm{T} 1$ and $\mathrm{T} 2$ relaxation times. As a result, the expected signal pattern for melanotic melanoma is hyperintensity in relation to cortex on $\mathrm{T} 1$-weighted images, hypointensity in relation to cortex on T2-weighted images, and isointensity or hypenintensity in relation to cortex on proton density-weighted images. The expected signal pattern for amelanotic melanoma is similar to that for other brain tumors: hypointensity or isointensity in relation to cortex on $\mathrm{T} 1$-weighted images and hyperintensity on isointensity in relation to cortex on T2- weighted images 2 .

A brain abscess could also be considered from the ring enhancement on enhanced T1WI. By conventional MRI, the typical brain abscess has low signal intensity on T1WI and high signal intensity on T2WI. They show ring enhancement after intravenous contrast injection. Differential diagnosis between cerebral abscesses in capsule stage, hydatic cyst, the ring enhancement of a cystic or necrotic high-grade glioma, and metastasis had to be done ${ }^{3}$. On the contrary, differential diagnosis of the brain lesions which were cystic or necrotic is difficult by using conventional MRI. Typically, contrast-enhanced MRI reveals ring 
enhancement of a brain abscess that is similar to cystic or necrotic high-grade glioma, and metastasis. Clinically, the neurological symptoms, the absence of hyperthermia and/or infectious symptoms in abscesses may often lead to an erroneous diagnosis. However, early identification of a brain abscess is important, because this potentially fatal lesion can be treated successfully by stereotaxic aspiration and antibiotic therapy.

Management strategies, which were concerning the malign melanomas, include symptomatic treatment with corticosteroids and anticonvulsants, and definitive therapy in the form of whole-brain radiation therapy, surgical resection, stereotactic radiosurgery, and systemic therapy ${ }^{5}$. There have been few previous reports about intracranial cystic amelanotic melanomas ${ }^{2,6}$.

The clinical course of the presented patient was more likely to be a metastatic melanoma instead of abscess. Considering the possibility of an abscess and the mass effect of the lesion, emergent surgery was performed. In the case reported here, we could not ascertain that the intracranial tumour was an amelanotic melanoma from the MR images alone using these definitions, but the images were highly suggestive of such.

An extremely rare case of intracranial metastatic amelanotic melanoma with cyst is presented. The malignant melanoma metastasis can show distinct appearances and the physicians have to be aware of these radiological variability about malignant melanoma metastases.

\section{References}

1. Bafaloukos, D., Gogas, H.: The treatment of brain metastases in melanoma patients. Cancer Treat Rev. 2004; 30: 515-520.

2. Isiklar, I., Leeds, N.E., Fuller, G.N., et al.: Intracranial metastatic melanoma: correlation between MR imaging characteristics and melanin content. AJR Am J Roentgenol. 1995; 165: 1503-1512.

3. Nadal Desbarats, L., Herlidou, S., de Marco, G., et al.: Differential MRI diagnosis between brain abscesses and necrotic or cystic brain tumors using the apparent diffusion coefficient and normalized diffusion-weighted images. Magn Reson Imaging. 2003; 21: 645-650.

4. Stone, A., Cooper, J., Koenig, K.L., et al.: A comparison of survival rates for treatment of melanoma metastatic to the brain. Cancer Invest. 2004; 22: 492-497.

5. Tarhini, A.A., Agarwala, S.S.: Management of brain metastases in patients with melanoma. Curr Opin Oncol. 2004; 16: $161-166$.

6. Vanzieleghem, B.D., Lemmerling, M.M., Van Coster, R.N.: Neurocutaneous melanosis presenting with intracranial amelanotic melanoma. AJNR Am J Neuroradiol. 1999; 20: 457-460.

7. Woodruff, W.W. Jr., Djang, W.T., McLendon, R.E., et al.: Intracerebral malignant melanoma: high-field-strength MR imaging. Radiology. 1987; 165: 209-213.

Cemil, B.; Emmez, H.; Oztanır, N.; Tokgoz, N.; Dogulu, F.: A cystic amelanotic melanoma metastasis to the brain: case report. Neurocirugía 2008; 19: 365-367.

Corresponding author: Berker Cemil. Gazi Üniversitesi Hastanesi, Beyin ve Sinir Cerrahisi Anabilim Dalı, Beşevler, 06500, Ankara. Turkey. 